\title{
A consolidação de grupos de aprendizagem em projeto de formação continuada
}

\section{The consolidation of learning groups in the continuing education project}

\section{Fernanda Keila Marinho da Silva ${ }^{[a]}$, Viviane Lousada Crace $\left.\right|^{[b]}$, Maurício Compiani ${ }^{[c]}$}

[a] Professora do Departamento de Física, Química e Matemática da Universidade Federal de São Carlos (UFSCar), Sorocaba, SP - Brasil, e-mail: fernandakeila@ufscar.br

[b] Doutoranda em Ensino e História de Ciências da Terra, Universidade Estadual de Campinas (Unicamp), Campinas, SP - Brasil, e-mail: viviane.lousada@gmail.com

[c] Doutor em Educação, professor da Universidade Estadual de Campinas, Campinas, SP - Brasil, e-mail: compiani@ige.unicamp.br

\section{Resumo}

Este artigo relata e discute a importância e a consolidação de um grupo de estudos formado por professores da Educação Básica e acadêmicos em uma proposta de trabalho colaborativo. Partindo de enunciados produzidos pelos próprios professores e de registros obtidos com a participação em reuniões coletivas, o texto destaca a existência dos avanços reflexivos 
dos docentes e a dificuldade dos acadêmicos em lidar com entraves vividos pelos professores na experiência formativa. Essa análise baseia-se na perspectiva bakhtiniana acerca do enunciado, que pressupõe a interação social como forma de compreender os episódios citados neste trabalho. Conclui enfatizando a importância da consolidação do grupo para a construção de caminhos reflexivos da parte dos acadêmicos e professores e discutindo aspectos da compreensão da pesquisa colaborativa entre escola pública e universidade..

Palavras-chave: Grupos de aprendizagem. Pesquisa colaborativa. Bakhtin.

\section{Abstract}

This paper reports and discusses the importance and the consolidation of a study group composed by basic education teachers and academics in a collaborative proposal. Based on enunciated produced by teachers and records obtained from participation in collective meetings, this paper highlights the existence of reflexive advances of teachers and students' difficulty to deal with barriers faced by teachers in their formative experience. This analysis is based on bakhtinian perspective on the enunciated, which involves social interaction as a way to understand the episodes cited in this paper. It concludes emphasizing the importance of consolidation of the group to the construction of reflective ways for academics and teacher and seeking a clarification of understanding of collaborative research.

Keywords: Learning groups. Collaborative research. Bakhtin.

\section{Introdução}

Não são poucos os trabalhos acadêmicos que apresentam os frutos advindos das pesquisas colaborativas. Em geral, os artigos e livros publicados sobre o tema nos mostram o caminho de formação privilegiado no processo (MIZUKAMI et al., 2002) ou, ainda, proporcionam uma 
reflexão mais teorizada acerca das concepções da pesquisa colaborativa e trabalhos em equipe (CLARK et al., 1996; WASSER; BRESLER, 1996). Em geral, esses trabalhos mostram com clareza o grande benefício "teórico" para os pesquisadores e o benefício "reflexivo" para os professores.

Tais pesquisas representam farto material para o assunto mais geral acerca da formação de professores, pois sinalizam vias positivas de trabalhos que vão além da instrumentação técnica, tão em voga no passado recente das propostas de formação docente (KINCHELOE, 1997; MIZUKAMI et al., 2002; PIMENTA et al., 2000; SCHÖN, 1987, 1992, 1998). Nesse sentido, avançam primordialmente na abordagem crítica e reflexiva na constituição do desenvolvimento profissional.

Este artigo se insere nesse universo de trabalhos, posicionando-se a favor das práticas de colaboração e pretende apresentar parte das vivências em uma prática colaborativa. Deseja-se aqui enfatizar diálogos e textos de um grupo de professores participantes de um projeto de formação continuada, analisando-os à luz da manifestação dialógica da linguagem existente nos momentos de coletividade desse grupo. Apesar dos números crescentes de trabalhos legitimando a pesquisa colaborativa, parece-nos que poucos a colocam sob análise a partir da perspectiva da linguagem. De modo mais geral, o que se pretende com essa abordagem é refletir sobre a potencialidade da consolidação de grupos de professores e acadêmicos no interior da escola. A análise será realizada a partir de textos retirados do diário de campo da observadora participante e de relatórios redigidos por professores participantes da proposta formativa citada anteriormente.

A importância dessa perspectiva está no delineamento mais preciso acerca das ocorrências do grupo quando universidade e escola se encontram rotineiramente, fazendo circular discursos e posicionamentos relativos a essa vivência. Essa opção também se reflete em nossa concepção de formação de professores, pois acredita-se que o grupo social dos professores são geradores de uma "cultura própria" (PIMENTA; GARRIDO; MOURA, 2001), que partilha valores, crenças, objetivos, desejos, enfim, signos da prática profissional. Ao expor fragmentos desses 
signos, reforçando e apresentando a diversidade e a intensidade dessas vivências, este artigo ancora-se na valorização da prática docente como responsável, em constante evolução e importante prática social.

O grupo ao qual fazemos referência neste trabalho se inseria no projeto Ribeirão Anhumas na Escola ${ }^{1}$, uma proposta que pressupunha, para a formação continuada, a parceria entre a escola pública e a universidade, caracterizando o que nomeamos como pesquisa colaborativa. Nossa participação nesse coletivo de professores ocorreu a partir do acompanhamento desse grupo em reuniões semanais, nas quais procurávamos assessorar os professores nas questões burocráticas, teóricas e práticas do referido projeto, tentando concatenar as necessidades e dúvidas dos professores e as necessidades e dúvidas da equipe da universidade. É importante deixar claro que nosso papel, como membros da universidade, não era avaliar os professores ou supervisionar suas reuniões, mas acompanhar suas reflexões visando compreender a maneira como mobilizavam suas ações e seus saberes, rumo à concretização prática das propostas elaboradas conjuntamente em suas respectivas salas de aula.

O primeiro ano do projeto foi marcado por dinâmicas para a formação continuada do grupo de professores das duas escolas participantes (E. E. Professora Ana Rita Godinho Pousa e E. E. Adalberto Nascimento) ${ }^{2}$, constituídas por oficinas sobre os eixos temáticos e disciplinares; por

1 O projeto tem como título "Elaboração de conhecimentos escolares e curriculares relacionados à ciência, à sociedade e ao ambiente na escola básica com ênfase na regionalização a partir dos resultados de projeto de Políticas Públicas" (Processo FAPESP n. 2006/01558-1) e foi coordenado pelo prof. Dr. Maurício Compiani, do Departamento de Geociências Aplicadas ao Ensino (DGAE), do Instituto de Geociências da Unicamp, em parceria com o Instituto de Biologia (IB) da Unicamp, Instituto Agronômico de Campinas (IAC), e as escolas E.E. Adalberto Nascimento e E.E. Professora Ana Rita Godinho Pousa. O projeto conta, ainda, com o apoio financeiro da FAPESP e do CNPq e patrocínio da Petrobras Ambiental, com atividades previstas para quatro anos (2007 a 2010). É importante destacar que esse projeto representa uma continuidade de outro projeto relacionado a políticas públicas, onde se buscou desenvolver um diagnóstico sócio ambiental da bacia do Ribeirão das Anhumas, em Campinas (TORRES et al., 2006).

2 Embora o período de formação tenha envolvido as duas escolas, o acompanhamento relatado neste artigo se refere somente ao da Escola Estadual Professora Ana Rita Godinho Pousa.

Rev. Diálogo Educ., Curitiba, v. 14, n. 42, p. 457-476, maio/ago. 2014 
reuniões de estudo e planejamento, caracterizadas por momentos de preparação e avaliação das atividades realizadas, assim como discussões e aprofundamento de alguns temas, buscando uma visão crítica e reflexiva a respeito das questões socioambientais, em especial referentes à bacia do Ribeirão Anhumas, a fim de possibilitar ações e intervenções no local. A execução das atividades e oficinas pedagógicas resultou em uma carga horária de 328 horas de trabalho. O segundo ano configurou-se como algo mais prático e delimitado, até certo ponto, no interior da escola. Nesse momento, os professores se articularam na construção de projetos de ensino e de pesquisa que seriam aplicados no próximo ano. Ocorreu então a construção de algumas práticas de ensino pelos professores, com suas turmas, visando iniciar as ações do projeto. O terceiro ano representou um momento de intensa atividade, uma vez que os professores se voltavam para a introdução de temas e práticas elaboradas no ano anterior. Foi nesse ano que os professores coletaram grande quantidade de dados na forma de relatórios, atividades e trabalhos de campo. São fragmentos desse processo que trazemos aqui.

\section{A pesquisa colaborativa na formação de professores}

A pesquisa colaborativa que compreendemos nesse trabalho pode ser caracterizada como aquela que acontece para e junto às escolas e professores. É diferente da concepção de pesquisa que advoga em favor de trabalhos sobre a escola e os professores. Nesse sentido, concordamos com Garrido, Pimenta e Moura (2000), autores que caracterizam o projeto de formação continuada por eles desenvolvido, cujo fim foi

promover o desenvolvimento profissional de pesquisadores e professores, favorecer mudanças na cultura organizacional da escola parceira, aprofundar o conhecimento sobre os processos de construção dos saberes pedagógicos pela equipe escolar e oferecer subsídios para políticas públicas de formação em serviço (GARRIDO; PIMENTA; MOURA, 2000, p. 94-95). 
Além desses objetivos, acrescentamos o interesse dos pesquisadores em conhecer os processos de aprendizagem desenvolvidos pelos professores na formação continuada. O estabelecimento desse tipo de trabalho pressupõe quesitos importantes do ponto de vista educacional. Um deles se refere ao fato do reconhecimento de que

[...] a formação de professores e especialistas de ensino não se constrói por acumulação de informações, cursos, técnicas, mas pelo aprendizado e exercício, individual e coletivo, da reflexão crítica sobre as práticas e os contextos de trabalho, oportunizando reconstrução da identidade profissional e pessoal (GIOVANI, 1998, p. 2).

A pesquisa colaborativa é, portanto, uma oportunidade de romper com esse viés tecnicista na formação de professores, por apoiar trabalhos reflexivos e compartilhados com outros participantes da colaboração. Clark et al. (1996) e Mizukami (2003) ressaltam que parece não haver um consenso em relação ao significado de pesquisa colaborativa e trazem diferentes autores para discutir a questão. Contudo, Mizukami (2003, p. 209) afirma ser possível identificar uma característica que permeia as diversas compreensões de colaboração e de pesquisa colaborativa: "a potencialidade para melhorar o desenvolvimento profissional por meio de oportunidades para a reflexão sobre a prática, críticas partilhadas e mudanças apoiadas". Tal concepção também perpassa os autores trazidos por Clark et al. (1996) em seu artigo, os quais apontam para algo de extremo interesse: apesar da natureza similar entre todas as definições de pesquisa colaborativa, o potencial desenvolvimento profissional dessas relações parece algo unilateral.

De fato, essa é uma dimensão importante da pesquisa colaborativa que precisa ser considerada. Até que ponto as mudanças são bem-vindas para os professores? E como podemos avaliar tal dimensão? E, de fato, como se constituem as mudanças na prática dos pesquisadores? É possível que esse artigo não dê conta de responder a todos esses questionamentos, mas pretende avançar em possibilidades para algumas dessas reflexões. 
Em geral, as propostas colaborativas tendem a aproximar-se de uma perspectiva que enfoca os problemas reais vividos no âmbito escolar, tentando desnaturalizar o pressuposto de que o processo de ensino se constitui como simples tarefa. Nesse sentido, se para as escolas essa perspectiva parece concebível para o trabalho dos professores, na realidade do universo acadêmico isso não é tão natural assim. "O trabalho de pesquisa em colaboração com professores e demais profissionais da escola nem sempre é considerado, dentro da universidade, como um trabalho com legitimidade acadêmica e científica" (GIOVANI, 1998).

Ao romper com uma concepção tecnicista de formação de professores, a pesquisa colaborativa reconhece o professor como sujeito do conhecimento e do ensino, e os papéis dos diferentes membros são dados como algo em permanente construção, por meio do diálogo constante visando, em última medida, o desenvolvimento profissional de acadêmicos e professores da Educação Básica.

Embora os sujeitos estejam constituídos pelo saber que trazem consigo e que os tornam competentes para desenvolver a investigação, em sua interação, esses mesmos sujeitos se resignificam como produtores de conhecimento e não apenas como usuários desse mesmo tipo de conhecimento e constroem novos papéis e possibilidades de relação entre eles (RODRIGUEZ; GARZÓN, 2006, p. 227-228).

Outro fator sobre o qual se tende a concordar com Clark et al. (1996) diz respeito à crença de que o diálogo deve ser peça central de todas as trocas. "Nós vemos essa questão como uma diferença fundamental na colaboração - que caracteriza um compartilhamento e as trocas mútuas não em termos de fazer o mesmo trabalho de pesquisa, mas, preferencialmente, em termos da compreensão do trabalho de cada um" (CLARK et al., 1996, p. 196). Assumem que essa perspectiva é sutil, mas também crítica, pois serve para nivelar o campo de atuação de uma forma que permite aos professores e pesquisadores colherem, igualmente, os benefícios da colaboração. 
Ancorados nessa importância do diálogo, propomo-nos a refletir sobre a compreensão dos diálogos existentes em nosso acompanhamento nessa pesquisa colaborativa. Como membros da universidade, interessa-nos a reflexão acerca do impacto dessa parceria na constituição profissional dos professores: o que ocorria nas reuniões semanais e demais espaços de socialização e que poderíamos caracterizar como algo de relevância para a prática profissional dos professores e para a compreensão da importância da participação da universidade na articulação de temáticas para esse desenvolvimento profissional? Esse problema específico de pesquisa permite o delineamento de uma boa reflexão acerca de como se constitui a pesquisa colaborativa numa proposta de formação continuada. Representa uma pequena parte de nossas dúvidas e nossos anseios com relação a essa prática, mas já aponta sinais para uma compreensão em torno desse tipo de pesquisa.

\section{A configuração de enunciados como perspectiva de análise}

Como analisar fragmentos de falas e fragmentos de anotações de um diário de campo sem cair na armadilha de uma possível "transparência da palavra"? Como analisar tais enunciados, considerando que somos (nós, da universidade) parte constitutiva do grupo de professores? Como transcender a uma análise meramente descritiva e avaliativa, originada de um "lugar social" que determina autoridade e saber, como é o caso da universidade? Tais questões nortearão nossa explicação em favor da perspectiva analítica sócio-histórica, que encontra nos textos de Bakhtin um importante referencial para análise.

Nesse sentido, os textos coletados não poderiam equivaler àquilo que a materialidade linguística trazia de maneira pronta e direta. Uma opção metodológica que nos auxiliou para a superação desses pressupostos acerca da linguagem foi a compreensão dos textos dos professores e dos acadêmicos como enunciados. 
A concepção de Bakhtin acerca do enunciado pressupõe que nele estejam incluídos, além dos fatores linguísticos que o constituem, elementos de ordem extraverbal, o que inclui os interlocutores e o contexto. De fato, tais elementos respondem a campos abrangentes que incluem uma diversidade de outros fatores, por exemplo, a quem se dirige o enunciado, de que maneira se definem os interlocutores, em que contexto os enunciados são trocados, a compreensão das falas entre os interlocutores etc. Bakhtin (2000, p. 318) coloca com clareza:

O enunciado é um fenômeno complexo, polimorfo, desde que o analisemos não mais isoladamente, mas em sua relação com o autor (o locutor) e enquanto elo na cadeia da comunicação verbal, em sua relação com os outros enunciados (uma relação que não se costuma procurar no plano verbal, estilístico-composicional, mas no plano do objeto do sentido).

O enunciado se erige da interação verbal, assinalada no Marxismo e na Filosofia da Linguagem como a verdadeira substância da língua. E a interação verbal se realiza por meio da enunciação. É também na enunciação, posta como interação social, que nasce o conteúdo ideológico que banha nossa consciência e que é responsável pela produção dos signos. O caráter ideológico do signo, tomado neste texto como a palavra, é o que modula nossa análise e o que nos permite tratar a palavra como o "fenômeno ideológico por excelência" (BAKHTIN, 2004, p. 36).

Considerando a palavra como produto ideológico, percebemos que ela funciona

[...] em qualquer situação social (leia-se aqui ideológica), tornando-se signo ideológico porque acumula as entoações do diálogo vivo dos interlocutores com os valores sociais, concentrando em seu bojo as lentas modificações ocorridas na base da sociedade e, ao mesmo tempo, pressionando uma mudança nas estruturas sociais (STELLA, 2005, p. 178). 
A análise que segue refletirá melhor e mais claramente a categoria de enunciado aqui disposta. Procurar-se-á apresentar os resultados advindos dessa consideração, visto que ela tem como pressuposto um determinado sujeito: multifacetado e inacabado, que traz em sua história marcas profundas de seus enunciados, como também do outro:

O enunciado está repleto dos ecos e lembranças de outros enunciados, aos quais está vinculado no interior de uma esfera comum da comunicação verbal. $\mathrm{O}$ enunciado deve ser considerado acima de tudo como uma resposta a enunciados anteriores dentro de uma dada esfera (a palavra 'resposta' é empregada aqui no sentido lato): refuta-os, confirma-os, completa-os, baseia-se neles, supõe-nos conhecidos e, de um modo ou de outro, conta com eles (BAKHTIN, 2000, p. 316).

Um elemento constitutivo de todo enunciado é a dimensão dialógica, característica vital da linguagem e que dela não pode ser abstraída, sendo condição de seu sentido; ou seja, ainda que as diversas vozes não apareçam em sua estrutura composicional, o enunciado é dialógico. O dialogismo, além de ser a noção fundante da concepção bakhtiniana de linguagem, é o elemento que instaura sua natureza interdiscursiva. Referese, portanto, ao constante diálogo, nem sempre simétrico e harmonioso, entre os diversos discursos que configuram a enunciação e que se realizam nas e pelas interações sociais. Cada discurso, intencionalmente ou não, interage com outros discursos antecedentes ou que o sucedem. Ele não é individual, pelo contrário, possui uma dimensão intertextual que pode ser caracterizada tanto pela presença de pelo menos dois interlocutores, duas vozes que constroem esse discurso, quanto pelo fato de manter relações dialógicas com outros discursos na enunciação.

Para Bakhtin (2004, p. 127), o diálogo é concebido como um processo que ultrapassa a interação face a face, que é apenas uma das condições em que ele ocorre, pois compreende "a palavra 'diálogo' num sentido amplo, isto é, não apenas como a comunicação em voz alta, de pessoas colocadas face a face, mas toda a comunicação verbal de qualquer tipo que 
seja”. São essas vozes e relações, por meio dos enunciados, que pretendemos mostrar com os exemplos a seguir.

\section{Interlocução como constituinte da pesquisa colaborativa: o que nos revelam os enunciados?}

Os enunciados apresentados neste tópico foram retirados de várias fontes documentadas do Projeto, especialmente daquelas concebidas em reuniões, existentes no diário de campo da observadora participante ${ }^{3}$ que acompanhava o grupo semanalmente. Foram também retirados dos relatórios dos professores ou dos fóruns de discussão possibilitados pela ferramenta Teleduc $c^{4}$. Estão transcritas exatamente do modo como foram retiradas dessas fontes e não representam respostas dadas em entrevistas a partir de questões específicas.

A fim de caracterizar esse processo dialógico, é importante não só situar o contexto mais geral da produção desses enunciados (o Projeto Ribeirão Anhumas na Escola), mas também esclarecer os interlocutores. Nos casos aqui apresentados, os textos circulavam num universo bastante heterogêneo composto por professores da escola pública, estudantes de pós-graduação e graduação e professores pesquisadores da universidade. Em geral, não há como demarcarmos assuntos específicos para cada fragmento apresentado neste artigo, uma vez que os diálogos circulavam em diferentes suportes: textos que tinham por meta descrever atividades desenvolvidas, relatórios que descreviam e analisavam as ações

3 A observadora participante esteve com os professores durante cerca de dois anos, com o objetivo de desenvolver seu trabalho de conclusão de curso e seu trabalho de iniciação científica. Para maiores detalhes acerca desse trabalho, veja Cracel (2008).

4 O Teleduc é um ambiente criado pelo Núcleo de Informação Aplicada à Educação (Nied) da Unicamp e utilizado para a educação a distância.

5 A discussão sobre a prática colaborativa no referido projeto pode ser encontrada em Silva (2013). 
implementadas por professores e acadêmicos, chats e fóruns conduzidos por mediadores da academia etc.

Os fragmentos expostos a seguir compõem parte do sistema empírico de nossa pesquisa e serão revelados seguidos da discussão propiciada pelo referencial bakhtiniano:

Eu sou uma outra pessoa, então eu vejo isso por mim, porque eu vivenciei né? Foram 49 anos vivendo de uma certa maneira, com pessoas que pensavam de uma maneira. De repente, em um ano eu modifiquei... Não é só meu modo de pensar, eu modifiquei os meus hábitos, eu modifiquei por dentro... Eu não sou mais igual. Então eu penso assim: se eu não sou mais igual meus alunos também podem não ser [...] Se eu me modifiquei, eles também podem [...] (Professora de Matemática - diário de campo, 18 de março de 2008).

Realmente, repensar é o que estamos mais fazendo em nossos encontros e em nosso dia a dia. As reuniões que tivemos sobre projetos escolares nos abriram outras ideias na mente. As práticas já não são mais as mesmas (Professora de Português - Fórum de discussão Reflexões sobre o projeto, 18 de setembro de 2007).

Os dois primeiros enunciados representam o contexto inicial do Projeto Anhumas (ano de 2007 e início de 2008). É importante situar o leitor de que, nessa fase, o processo era muito mais dependente da execução dos eixos/aulas e atividades propostos pelos formadores. Os professores eram participantes ativos, que dialogavam em aulas, propunham e desenvolviam exercícios, porém ainda não se fazia necessário o enlace entre o "aprendido" no projeto e a sala de aula. Estávamos num momento de relativa "tranquilidade" do processo formativo, em que as reflexões voltavam-se somente à vivência do professor com a universidade. Representava a inserção do grupo dos professores em um outro grupo: o dos acadêmicos e vice-versa. Esse início não exigia uma interlocução mais profunda entre os grupos, pois os formadores ministravam oficinas e os professores participavam delas. Reflexões, opiniões, conversas informais se bastavam e mostravam o acerto metodológico e 
temático da formação privilegiada pelos formadores. Deixam-nos claras diversas vantagens do processo colaborativo, visto que são enunciados que partiram dos professores do projeto.

São importantes, sobretudo, por trazerem a ideia da "transformação" vivenciada pelos professores. Falas como: "Eu me modifiquei..." ou "As práticas já não são as mesmas..." apontam direções que culminam numa ruptura da inércia tradicional a que os professores são costumeiramente rotulados em sua profissão. Dessa forma, expõem a vontade de aprender e a satisfação da modificação reconhecida pelos professores no processo. Sobressaem marcas profundas da relação entre docência e processo de desenvolvimento profissional: numa sociedade que considera o professor o "culpado" dos problemas educacionais, percebemos que a melhoria ou a incitação de reflexões é bem-vinda em sua vivência. Nota-se que processos que legitimam o desenvolvimento profissional dos professores de forma a respeitá-los em suas diferenças são considerados exitosos, bem-vindos, mesmo que isso os sobrecarregue ainda mais.

O contato com a academia nos proporcionou momentos de reflexão, que antes passavam despercebidos, e sugere um estudo constante. Esta necessidade de estudo nos colocou em contato com assuntos pertinentes ao nosso dia a dia como docentes, além de nos proporcionar novos conhecimentos (Retirado do projeto pedagógico, $1^{\circ}$ semestre de 2007, p. 6).

Novamente, os professores mostram que o contato com a universidade foi importante. Dessa vez, enfatizando que os acadêmicos mostravam reflexões que antes passavam despercebidas por eles mesmos. Longe da percepção, de que maneira produzir sua própria prática e a mudança diante dos problemas/conteúdos/vivências? A reflexão sobre a ação não é caminho simples e automaticamente gerado. É intrinsecamente vinculado à mediação. É nesse sentido que Bakhtin e tantos outros autores que o seguem enfatizam a importância do "outro" para o desenvolvimento do "eu" individual. Compreendemos, dessa maneira, que "[...] o desenvolvimento no plano do pensamento não é do individual para o socializado [...], mas, antes, do social para o individual [...]" (CLARK; 
HOLQUIST, 2004, p. 249). A coletividade que se produz auxilia na construção de reflexões, fornece percepções e abre caminhos reflexivos.

Trabalhar com o coletivo não é coisa fácil, principalmente quando temos espaços restritos para discussões. O projeto está nos possibilitando esses espaços. Eu acho que daremos conta de elaborar movimentações interdisciplinares, é só uma questão de tempo para que tudo isso se transforme em realidade na escola (Professora de Biologia - Fórum de discussão Interdisciplinaridade, 17 de abril de 2007).

Tais reuniões [de estudo e planejamento] proporcionaram um tempo e um espaço que não tínhamos para discutir nossa prática, para estudos teóricos, para troca de experiências e para, coletivamente, expor e aprimorar nossas ideias e atividades etc. (Retirado do projeto pedagógico, $1^{\circ}$ semestre de 2007, p. 5).

Esses dois últimos enunciados trazem o assunto acerca da criação de espaços de reuniões entre os professores. Isso representou uma exigência por parte da coordenação do projeto, a fim de que as elaborações das atividades e a própria formação continuada fossem dependentes do coletivo de professores e da relação desse coletivo com as finalidades da escola.

Apesar da dificuldade em concatenar horários para tais reuniões, elas se mostraram viáveis, à medida que o grupo adquiriu certa "identidade" com sua configuração - "Houve um considerável fortalecimento $e$ aproximação do grupo de professores participantes, tornando-o mais coeso e participativo, com as reuniões semanais" (Projeto Pedagógico, $1^{\circ}$ semestre de 2007, p. 3). Essa identidade pode ser verificada também a partir da maneira como os professores se referem uns aos outros, tornando nítida, novamente, a importância crucial desse "outro" na constituição dos indivíduos: "O projeto está nos possibilitando..."; "Eu acho que daremos conta..."; "Tais reuniões proporcionaram um tempo e um espaço que não tínhamos para discutir...". A referência ao outro nas falas dos professores 
reveste de importância a configuração de uma ação que se deseja grupalizante, não deixando de salientar, contudo, a dificuldade desse trabalho.

Novamente, nesse contexto, algo importante a se destacar na configuração de uma identidade coletiva é a criação de uma "cumplicidade" do grupo para enfrentar os problemas vivenciados pelos professores, dos quais as imposições de secretarias, direção, carência de horário para estudo são somente alguns exemplos. Além disso, a identidade construída no coletivo reverbera na própria condição de trabalho, visto que o coletivo possui uma "autoridade" maior para provocar pressões na estrutura organizacional da escola para discussões acerca de práticas.

Durante a reunião... alguns relatos dos professores. A prof. ${ }^{a}$ Patrícia assinalou a dificuldade que está enfrentando: empacou! O 3. ${ }^{\circ}$ ano faz quando acha que deve fazer... A prof. ${ }^{a}$ Sara entrou mais no conteúdo e deu uma parada no projeto. Relatou que sente muita dificuldade em trabalhar a interdisciplinaridade (Retirado do diário de campo - Reunião de Estudo e Planejamento, 12 de agosto de 2008).

A dificuldade inerente a qualquer proposta que não seja mera reposição ou atualização de conteúdos se faz sentir no grupo de maneira contundente e produz ciclos de reclamação constantes nos momentos de reunião.

Exemplificado aqui por duas professoras somente, essas posturas representavam uma dificuldade também para a equipe da universidade, pois embora a nós não coubessem as tarefas de sala de aula, a academia era, ao lado dos professores, uma das norteadoras dos processos vivenciados no processo formativo. A sensação de "empacamento" do trabalho pedagógico é desconfortável e deve ser compreendida de forma ampla, não pontual. Parece salutar que o Projeto, seus objetivos e cronogramas sofram ajustes decorrentes de sua dinâmica e de sua composição, pois é parte de uma atividade humana e solidamente dependente das interações sociais de professores, instituição, administração, alunos, conteúdos, universidade, agência de fomento etc. 
A equipe da universidade participava desses momentos tentando elucidar os motivos que teriam levado ao entrave das atividades, sugerindo trabalhos coletivos entre os professores, elaborando dinâmicas para sistematizar e compreender os problemas. Importante esclarecer que tais encaminhamentos não se constituíam como a melhor saída para os problemas, mas como uma possibilidade para enfrentá-los, dentre muitas existentes, uma vez que não possuíamos a resposta para muitas das perguntas.

Além desses apontamentos, é possível notar também formas de compreensão do projeto pelos professores. Quando a professora relata que "parou o projeto e entrou mais no conteúdo", cabe um questionamento sobre a(s) representação(ões) que possuem os professores (ou alguns deles) sobre o Projeto. Esse enunciado se desdobra em uma multiplicidade de vozes presentes no universo das escolas à medida que a demarcação dos conteúdos é predominante em relação a qualquer outra proposta que ocorra na escola. Nesse sentido, o "projeto" caminha paralelamente e distante de uma ação docente já consagrada: transmissão de conteúdos.

Às 19h30, iniciamos a reunião com todos os professores. Tivemos uma "briga" feia por causa da "imposição" da coordenação em dividir os grupos e misturá-los com a outra escola, durante o seminário do meio do ano. O mal-estar foi geral, uma vez que a Fernanda não cedeu, explicitando que sempre houve abertura para conversa, sem imposições, portanto, se eles quisessem, eles poderiam elaborar uma nova proposta de trabalho e reapresentá-la à coordenação (Retirado do diário de campo - Reunião de Estudo e Planejamento, 8 de julho de 2008).

Se os enunciados anteriores exaltam o grupo e a interação com a universidade para o delineamento do avanço profissional, o último fragmento mostra o quanto o trabalho colaborativo é carregado de conflitos que interferem diretamente nas atividades. Situações como essas ocorreram algumas vezes e explicitam que o convívio de dois grupos distintos requer abertura para o diálogo. Diálogo, por sua vez, pressupõe contato, concordância e, também, discordância. Naturalmente, o conflito não é vivido de maneira confortável, pois há desentendimento e desgastes 
ocorridos no processo, porém devemos reconhecer que ele possibilita a externalização desse conflito, atitude que indica, por seu turno, a maturidade para diálogos e vivências posteriores.

\section{Considerações finais}

A análise desenvolvida possibilita ampla margem de discussão para processos formativos que tenham por meta desenvolver a pesquisa colaborativa. Wasser e Bresler (1996) destacam que, durante muito tempo, permaneceu no âmbito das pesquisas qualitativas e quantitativas a imagem do pesquisador "solitário", que trabalha individualmente. Contudo, isso foi, paulatinamente, desmistificado com o surgimento das teorias sociais do desenvolvimento, que valorizam a natureza coletiva do conhecimento. Sob esse aspecto, os autores ressaltam que há poucos trabalhos publicados referentes ao papel do social nos processos interpretativos, como, por exemplo, as relações estabelecidas entre o pesquisador e os participantes e entre os próprios participantes. Além disso, as pesquisas encontradas descrevem o processo, porém não analisam o processo de formação de grupos de trabalho.

Em concordância com o que dizem os autores, foi objetivo deste artigo revelar, parcialmente, a dinâmica de encontros semanais entre pesquisadores e professores e, por meio dessa revelação, demonstrar a maneira como se constituiu um grupo de trabalho formado pela diversidade que comporta dois grupos sociais em convívio. Buscou-se ir adiante, apresentando não somente os benefícios alcançados, mas também parte dos percalços vivenciados nessa dinâmica. Dessa forma, pretendeu-se colaborar com a própria interpretação da finalidade e dos alcances da colaboração entre pesquisadores e demais grupos sociais (WASSER; BRESLER, 1996).

Reflexões acerca dos alcances da colaboração são mostradas por diversas pesquisas colaborativas ${ }^{5}$. Nesse sentido, este trabalho pode reafirmar a maior compreensão do papel e do próprio status da universidade por

5 A discussão sobre a prática colaborativa no referido projeto pode ser encontrada em Silva (2013). 
parte dos professores. Desmitifica-se a função do pesquisador e de seu local de trabalho quando esse se envolve diretamente com o público escolar não somente professores, mas também estudantes e demais agentes.

A dinâmica das reuniões, no caso aqui apresentado, procurava conferir "voz" aos professores, inaugurando um ambiente diferente do habitual. Sem dúvida, houve o fortalecimento do coletivo dos professores e o reconhecimento da importância do "outro" no processo formativo de cada um. Esse caminho delineou, em médio prazo (cerca de três anos), a reconstrução da identidade profissional (que pouco discutimos), uma vez que os professores puderam propor novas práticas didático-pedagógicas que visavam não à repetição de conteúdos estabelecidos, mas à abordagem de novos temas e recursos em suas práticas.

Para finalizar, defende-se aqui a legitimidade acadêmica e científica dos trabalhos desenvolvidos em colaboração entre professores e pesquisadores. É fundamental a proposição de metodologias formativas, porém elas precisam ser postas sob análise a partir de uma perspectiva que desconstrua certos equívocos e que, sobretudo, demonstre o processo complexo e dinâmico que as envolvem.

\section{Agradecimentos}

À FAPESP, pelo apoio concedido ao Projeto de Linha Regular intitulado "Pesquisa do professor e pesquisa colaborativa na formação continuada com temas geocientíficos", número de processo: 12/06170-2.

\section{Referências}

BAKHTIN, M. Estética da criação verbal. Tradução do francês de Maria Ermantina Galvão G. Pereira. São Paulo: Martins Fontes, 2000. 
BAKHTIN, M. (VOLOCHINOV). Marxismo e filosofia da linguagem. Tradução do francês de Michel Lahud e Yara Frateschi Vieira. 11. ed. São Paulo: Hucitec, 2004. Publicado originalmente em 1929.

CLARK, C. et al. Collaboration as dialogue: teacher and researchers engaged in conversation and professional development. American Educational Research Journal, v. 37, n. 1, p. 192-132, Spring 1996.

CLARK, K.; HOLQUIST, M. Mikhail Bakhtin. Trad. J. Guinsburg. São Paulo: Perspectiva, 2004.

CRACEL, V. L. A cartografia mediando o ensino: possibilidades e potencialidades. 2008. Monografia (Graduação em Geografia) — Universidade Estadual de Campinas, Campinas, 2008.

GARRIDO, E.; PIMENTA, S.G.; MOURA, M. O. A pesquisa colaborativa na escola como abordagem facilitadora para o desenvolvimento da profissão do professor. In: MARIN, A. J. Educação continuada: reflexões, alternativas. Campinas: Papirus, 2000. (Magistério: formação e trabalho pedagógico).

GIOVANI, L. M. Do professor informante ao professor parceiro: reflexões sobre o papel da universidade para o desenvolvimento profissional de professores e as mudanças na escola. Cadernos CEDES, v. 19, n. 44, abr. 1998.

KINCHELOE, J. L. A formação do professor como compromisso político: mapeando o pós-moderno. Trad. Nilze Maria Campos Pellanda. Porto Alegre: Artes Médicas, 1997.

MIZUKAMI, M. G. N. et al. Escola e aprendizagem da docência: processos de investigação e formação. São Carlos: EdUFSCAR, 2002.

MIZUKAMI, M. G. N. A pesquisa sobre formação de professores: metodologias alternativas. In: BARBOSA R. L. L. (Org.). Formação de educadores: desafios e perspectivas. São Paulo: Editora Unesp, 2003. p. 201-232. 
PIMENTA, S. G.; GARRIDO, E.; MOURA, M. O. Pesquisa colaborativa na escola facilitando o desenvolvimento profissional de professores. 2001. Disponível em: <http:// www.cefetes.br/gwadocpub/Pos-Graduacao/Especializa\%C3\%A7\%C3\%A3o\%20 em\%20educa\%C3\%A7\%C3\%A3o\%20EJA/Publica\%C3\%A7\%C3\%B5es/ anped2001/textos/sesselma.PDF>. Acesso em: 9 fev. 2010.

PIMENTA, S. G. et al. Qualificação do ensino público e formação de professores. Pro-Posições, v. 1, n. 4, p. 56-69, mar. 2000.

RODRIGUEZ, J. G.; GARZÓN, J. C. Cooperação escola-universidade e a construção do currículo. In: GARCIA, R. L.; MOREIRA, A. F. B. (Org.). Currículo na contemporaneidade: incertezas e desafios. São Paulo: Cortez, 2006. p. 209-253.

SCHÖN, D. A. Educating the reflective practitioner. San Francisco: Jossey-Bass, 1987. SCHÖN, D. Formar professores como profissionais reflexivos. In: NÓVOA, A. (Org.). Os professores e a sua formação. Lisboa: Dom Quixote, 1992.

SCHÖN, D. El professional reflexivo: cómo piensan los profesionales cuando actúan. Barcelona: Paidós, 1998.

STELLA, P. R. Palavra. In: BRAIT, B. (Org.) Bakhtin: conceitos-chave. São Paulo: Contexto, 2005.

TORRES, R. B. et al. Recuperação ambiental, participação e poder público: uma experiência em Campinas. 2006. Disponível em: <http://www.iac.sp.gov.br/projetoanhumas>. Acesso em: 2 jun. 2014.

WASSER, J. D.; BRESLER, L. Working in the interpretative zone: conceptualizing collaboration in qualitative research teams. Educational Researches, v. 25, n. 5, p. 5-15, Jun./Jul. 1996.

Recebido: 24/04/2013

Received: 04/24/2013

Aprovado: 20/04/2014

Approved: 04/20/2014 